\title{
Pleural Mesothelioma pN1 TNM Finding v7
}

National Cancer Institute

\section{Source}

National Cancer Institute. Pleural Mesothelioma pN1 TNM Finding v7. NCI Thesaurus. Code $C 88909$.

Pleural mesothelioma with metastases in the ipsilateral bronchopulmonary or hilar lymph nodes. (from AJCC 7th Ed.) 